\title{
Fostering adoption of conservation technologies: a case study with wildlife law enforcement rangers
}

\author{
Nicole Sintov, Viviane Seyranian and Arnaud Lyet
}

\begin{abstract}
New technologies can aid the success of conservation outcomes. Technology alone will not however guarantee conservation success; this hinges on user adoption. Hence, there is a need to understand users' adoption decisions and how to account for these to streamline the introduction of new technologies. Wildlife law enforcement rangers constitute a key end-user group for conservation technologies, and although some studies have focused on ranger experiences, and on the impacts of policing technologies on crime rates, few have addressed technology adoption among law enforcement personnel, and none among rangers. To address this gap we conducted a case study focused on a new technology called the Protection Assistant for Wildlife Security (PAWS), which was developed to deter poaching by improving the deployment of wildlife law enforcement ranger foot patrols. We evaluated the impacts of an educational programme on the willingness of Indonesia-based rangers to adopt the tool. Following the programme, rangers reported high levels of willingness to adopt PAWS. Furthermore, the more engaged rangers were in the programme, the more useful and easy to use they perceived PAWS to be, and the stronger their adoption intentions. In contrast, rangers who were more resistant to technology from the outset were less engaged in the programme, highlighting the importance of identifying and addressing sources of resistance. Overall, the findings of this case study stress the significance of accounting for and educating end users in disseminating conservation technologies, reinforcing the importance of accounting for human dimensions of conservation.
\end{abstract}

Keywords Conservation psychology, conservation technology, human dimensions, technology adoption, wildlife rangers

Supplementary material for this article is available at https://doi.org/10.1017/So030605317001533

\footnotetext{
Nicole SinTov* (Corresponding author) University of Southern California, Price School of Public Policy, Los Angeles, California, USA

E-mail sintov.2@osu.edu

Viviane Seyranian Psychology and Sociology Department, California State Polytechnic University, Pomona, USA

ARNAUd LyeT WWF, Washington, DC, USA

${ }^{*}$ Currently at: School of Environment and Natural Resources, 469B Kottman Hall, 2021 Coffey Road, Columbus, OH 43210, USA

Received 10 July 2017. Revision requested 12 September 2017.

Accepted 25 September 2017. First published online 5 February 2018.
}

$\mathrm{N}$ ew technologies can aid conservation efforts, but their success hinges on user adoption. Wildlife law enforcement rangers (hereafter referred to as rangers) are a key end-user group for adoption of new conservation technologies. This case study focuses on the adoption of rangerbased technologies that can aid in combatting wildlife crime.

Ranger-based technologies have been used for decades to gather information on patrol effort (e.g. person-hours), poaching and other illegal activity, and trends in wildlife populations (Jachmann, 2008). The digital capture of standardized spatial data has facilitated new ways of maximizing the value of such data; for example, using technologies such as global positioning system (GPS) devices for recording geo-tagged photographs (Lemieux, 2015), and the Spatial Monitoring and Reporting Tool (SMART), rangers can record data digitally while on patrol. Such information can enhance ranger effectiveness and potentially reduce illegal activity (Hilborn et al., 2006; Jachmann, 2008; Critchlow et al., 2016). Although there is an increasing body of literature on ranger experiences (Jachmann, 2008; Eliason, 2011; Filteau, 2012; Moreto et al., 2016), little is known about factors that contribute to the adoption of conservation technology. In this study we developed and tested an educational intervention that aimed to promote adoption of a new patrol technology, the Protection Assistant for Wildlife Security (PAWS).

We tested variables from the Technology Acceptance Model (Venkatesh \& Bala, 2008), which describes the decision-making process in adopting information technologies, emphasizing perceived usefulness (the extent to which one believes technology will be useful) and perceived ease of use (the extent to which one believes technology will be easy to use) as two key determinants of adoption. Although an abundance of literature supports the Technology Acceptance Model in explaining technology adoption in traditional office settings (King \& He, 2006), and there is a burgeoning literature on the impacts of technology on crime rates and law enforcement organizations (Manning, 2008; Garicano \& Heaton, 2010), we identified only two studies that focused on technology adoption among law enforcement officers (Colvin \& Goh, 2005; Lindsay et al., 2011). Most germane to our investigation, Lindsay et al. (2011) concluded that low awareness of benefits of technology was a key barrier to adoption amongst police officers, recommending that future work highlight a technology's benefits to increase its perceived usefulness.

Although not covered in the Technology Acceptance Model, technology adoption may be hindered by technology 
resistance. For instance, in workplace settings some employees fear that innovations may interfere with routines, affect relationships with colleagues, reduce workplace autonomy, or increase workloads (Lapointe \& Rivard, 2005). Educational interventions have been recommended to reduce resistance (Venkatesh \& Bala, 2008), but we identified no evidence of their utility in this regard.

We aim to build on the Technology Acceptance Model by evaluating the role of educational intervention as well as resistance in rangers' perceptions of and willingness to adopt a new patrol technology. The study hypotheses are outlined in Table 1. Our study focuses on Sumatra because it has the highest concentration of threatened vertebrate species in Indonesia (Murray et al., 2015).

A 3-day workshop was developed and hosted in collaboration with WWF in Bandar Lampung, Sumatra, in May 2015, to introduce PAWS (Yang et al., 2014), which was developed to protect terrestrial wildlife from poaching. Rooted in computational game theory, PAWS employs security games, or game-based models of strategic interactions between two players, a defender (e.g. ranger) and an adversary (e.g. poacher). It uses data from protected areas (e.g. past poaching activity, topography, species distributions) to generate suggested patrol routes (e.g. route maps, heat maps, GPS waypoints; Tambe, 2011). Other game-theoretic applications have been developed to combat poaching (Park et al., 2015; Haas \& Ferreira, 2017), suggesting that such tools may become more available to conservation efforts. WWF invited employees of the five primary groups responsible for protecting wildlife on Sumatra to participate in the programme: the Indonesian National Park Service, WWF, the Wildlife Conservation Society, the Indonesian Rhino Foundation, and the Indonesian Prosecution Office. There were 29 participants ( 27 males, 2 females), with a mean age of $35 \pm$ SD 7.5 years.

The programme included three modules: (1) lectures, in which instructors introduced theoretical foundations and examples relevant to PAWS, along with its benefits; (2) discussions, in which participants exchanged ideas about challenges in wildlife protection; and (3) computer and board games, which participants played as a hands-on tutorial in security games. For more details, see Sintov et al. (2016). Participants completed surveys on the final day, which assessed basic demographics, Technology Acceptance Model constructs, technology resistance, and programme engagement (see Table 2 and Supplementary Material 1 for variable coding and construction). All procedures were approved by the University of Southern California Institutional Review Board (Study ID\# UP-15-00727).

To test $\mathrm{H}_{1}$ (Table 1 ) we computed mean values for relevant variables (Table 2). Confirming our H1 predictions, rangers evaluated PAWS positively following the programme, with a mean adoption intentions score of $5.89 \pm$ SD 1.13. Scores on other relevant technology acceptance variables, including
TABLE 1 Study hypotheses.

H1 Following programme implementation, participants will report high levels ${ }^{\star}$ of programme engagement, positive adoption intentions ${ }^{*}$, and positive evaluations of Technology Acceptance Model constructs ${ }^{*}$

H2 Programme engagement will be positively associated with adoption intentions

H3 Programme engagement will be positively associated with perceived usefulness

H4 Resistance to technology will be negatively associated with adoption intentions

H5 More resistant rangers will be less engaged in the programme

H6 More resistant rangers will be older

H7 More resistant rangers will have more field experience

${ }^{\star}$ Defined as $>$ scale medians

perceived usefulness, ease of use, job relevance, and output quality were also positive (above Likert scale midpoints; Table 2).

Several variables had non-normal distributions; hence, $\mathrm{H}_{2}, \mathrm{H}_{3}$ and $\mathrm{H}_{4}$ (Table 1) were tested using Spearman correlations. Correlation results (Table 3) suggested support for a modified version of the Technology Acceptance Model informed by our hypotheses (Fig. 1). Specifically, in line with the Technology Acceptance Model, perceived usefulness and perceived ease of use were both positively associated with adoption intentions; job relevance and output quality were positively associated with perceived usefulness. Building on the Technology Acceptance Model, programme engagement was significantly and positively correlated with adoption intentions and perceived usefulness, supporting $\mathrm{H}_{2}$ and $\mathrm{H}_{3}$, respectively. The relationship between technology resistance and adoption intentions trended in the predicted direction but was not significant, failing to support $\mathrm{H}_{4}$.

To test $\mathrm{H}_{5}-\mathrm{H}_{7}$ (Table 1 ) regarding characteristics of technology resistors, the sample was split into two groups based on median technology resistance score, categorizing users as low (score $\leq 2)$ or high $($ score $>2$ ) resistors. Independent samples t-tests evaluated possible group differences in age (normally distributed), whereas their non-parametric ana$\log$, the Wilcoxon-Mann-Whitney test, was used for nonnormal outcomes (years of work experience, programme engagement). Supporting $\mathrm{H}_{5}$, engagement was significantly higher $(z=2.02, \mathrm{P}<0.05)$ among the low (mean $=6.12 \pm \mathrm{SD}$ 0.30 ) vs high (mean $=5.57 \pm \mathrm{SD} 0.90$ ) resistance groups. Contrary to our H6 prediction, the low resistance group was significantly $(z=2.68, \mathrm{P}<0.01)$ older (mean $=$ $39.91 \pm \mathrm{SD} 4.57$ years) than the high resistance group (mean $=31.31 \pm S D 7.26$ years). We observed no relationship between years of work experience and resistance, thus failing to support $\mathrm{H}_{7}$.

In summary, our results support and extend the Technology Acceptance Model, thus advancing the 
TABLE 2 Key variables, with survey questions and descriptive statistics. For each independent variable, individual items were averaged and the resulting mean scale score used in all analyses. Unless otherwise indicated, response scales are 1 (strongly disagree) -7 (strongly agree).

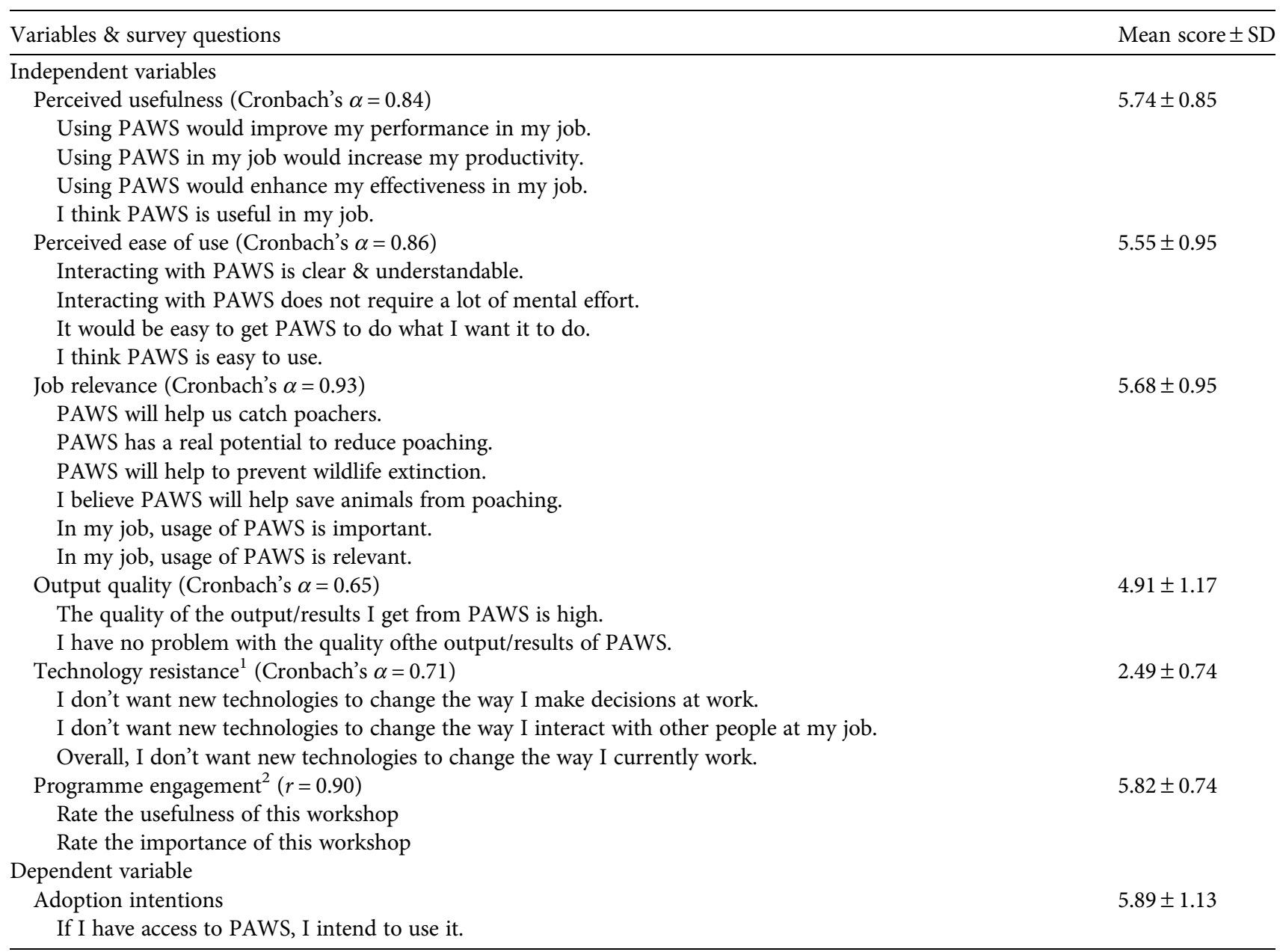

${ }^{1}$ Reverse scored: 1 (strongly disagree) -5 (strongly agree)

${ }^{2}$ Response scale: 1 (extremely useless/unimportant) -7 (extremely useful/important).

TABLE 3 Spearman correlations among key variables.

\begin{tabular}{|c|c|c|c|c|c|c|c|}
\hline & Usefulness & $\begin{array}{l}\text { Ease of } \\
\text { use }\end{array}$ & $\begin{array}{l}\text { Job } \\
\text { relevance }\end{array}$ & $\begin{array}{l}\text { Output } \\
\text { quality }\end{array}$ & $\begin{array}{l}\text { Technology } \\
\text { resistance }\end{array}$ & $\begin{array}{l}\text { Programme } \\
\text { engagement }\end{array}$ & $\begin{array}{l}\text { Adoption } \\
\text { intentions }\end{array}$ \\
\hline \multicolumn{8}{|l|}{ Usefulness } \\
\hline Ease of use & $0.73^{\star * *}$ & & & & & & \\
\hline Job relevance & $0.64^{* * *}$ & $0.83^{* * *}$ & & & & & \\
\hline Output quality & $0.40^{*}$ & $0.54^{* *}$ & $0.42^{*}$ & & & & \\
\hline Technology resistance & -0.25 & -0.06 & -0.23 & 0.06 & & & \\
\hline Programme engagement & $0.38^{\star}$ & $0.46^{\star}$ & $0.51^{\star *}$ & 0.18 & $-0.40^{*}$ & & \\
\hline Adoption intentions & $0.74^{* * *}$ & $0.53^{* *}$ & $0.54^{\star *}$ & $0.43^{*}$ & -0.21 & $0.41^{*}$ & \\
\hline
\end{tabular}

${ }^{* * *} \mathrm{P}<0.001,{ }^{* *} \mathrm{P}<0.01,{ }^{*} \mathrm{P}<0.05$

technology adoption literature. Specifically, whereas previous studies have merely recommended employing interventions to foster technology adoption (Venkatesh \& Bala, 2008), we provide preliminary evidence that supports the utility of these types of interventions in the field. Building on previous work showing that learner engagement is a key driver of learning outcomes (Carini et al., 2006), and that opportunities for learning contribute to ranger job satisfaction (Moreto et al., 2016), we found the more engaged rangers were in our programme, the stronger their intentions to adopt PAWS and the more useful they perceived it to be. Regarding resistance, rangers who were more 


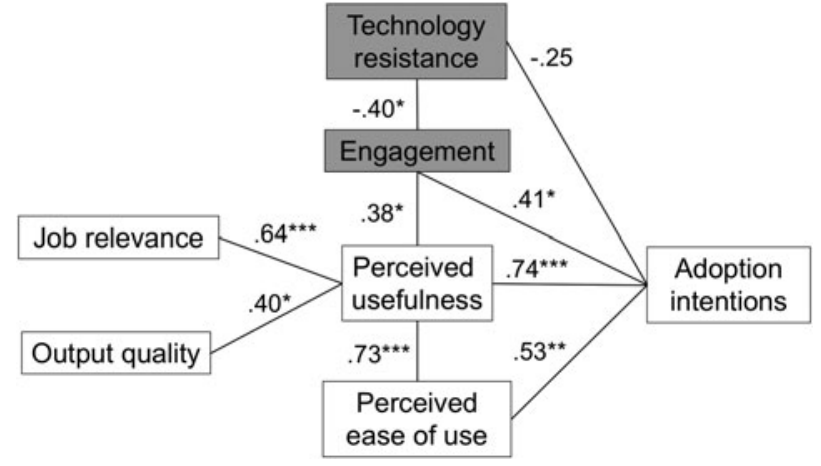

FIG. 1 Model constructs with bivariate correlations. Technology Acceptance Model variables are in white boxes; variables added in this study are in grey. ${ }^{\star *} \mathrm{P}<0.001,{ }^{* *} \mathrm{P}<0.01,{ }^{\star} \mathrm{P}<0.05$.

resistant to technology in general were younger and less engaged in the programme. One possibility for this finding is that younger rangers may have perceived PAWS as reducing their autonomy in making decisions, a theme that aligns with previous work (Lapointe \& Rivard, 2005; Lindsay et al., 2011). Alternatively, younger rangers may have had less confidence and/or trust in the accuracy of the models underlying PAWS than older rangers. Both themes were supported by qualitative data (not reported here). Reaching resistors in the first place may be particularly challenging, highlighting the importance of understanding and addressing sources of technology resistance (Venkatesh \& Bala, 2008).

Our findings should be considered in light of several limitations. Firstly, given the study's cross-sectional design, results are not causal. Future research should use experimental designs and control groups with pre/post measures to discern causal processes, and should also include validity checks (e.g. by assessing learning comprehension). Secondly, this study had a small sample size drawn from a relatively small population, which limited statistical modelling. Future studies should attempt to replicate these results using larger, multi-site samples and more advanced statistical techniques.

In conclusion, consistent with previous work (Gore, 2011; Bennett et al., 2016), this case study, which brought together several fields that do not traditionally intersect (i.e. psychology, wildlife management, criminology and computer science) as well as experts from the academic, government and NGO sectors, highlights the importance of including social science in conservation efforts. The study makes several contributions. In addition to extending the technology adoption literature, we also provide evidence that educational interventions can benefit the introduction of conservation technology. Whereas work on human dimensions of wildlife management tends to focus on local communities (Moreto et al., 2016), our study highlights an understudied, yet critically important group: the dedicated individuals working at the forefront of wildlife protection. Rangers will continue to play a key role in the success of conservation technologies, making the study of this group essential. Other work on frontline perspectives has yielded invaluable insights to improve conservation efforts (Jachmann, 2008; Eliason, 2011; Filteau, 2012; Moreto et al., 2016). We urge further work in this area.

\section{Acknowledgements}

We thank J. Charles, R. Mahmud and C. Ayu Wardani for their integral roles in planning and implementing the workshop, and S. Aratoon, J. Barash and E. Wezerek for their assistance with preparing the data. This work was supported by the U.S. Department of Defense Multidisciplinary University Research Initiative (grant \# W911NF-11-1-03) and WWF (PAWS anti-poaching grant).

\section{Author contributions}

All authors conceived and designed the research. NS analysed the data and wrote the initial draft of the article. VS reviewed several drafts and made significant revisions. AL reviewed and provided substantial feedback on several drafts.

\section{References}

Bennett, N.J., Roth, R., Klain, S.C., Chan, K.M.A., Clark, D.A., Cullman, G. et al. (2016) Mainstreaming the social sciences in conservation. Conservation Biology, 31, 56-66.

Carini, R.M., Kuh, G.D. \& Klein, S.P. (2006) Student engagement and student learning: testing the linkages. Research in Higher Education, 47, 1-32.

Colvin, C.A. \& GoH, A. (2005) Validation of the technology acceptance model for police. Journal of Criminal Justice, 33, 89-95.

Critchlow, R., Plumptre, A.J., Alidria, B., Nsubuga, M., Driciru, M., Rwetsiba, A. et al. (2016) Improving law-enforcement effectiveness and efficiency in protected areas using ranger-collected monitoring data. Conservation Letters, http://dx.doi.org/10.1111/conl.12288.

Eliason, S.L. (2011) Policing natural resources: issues in a conservation law enforcement agency. Professional Issues in Criminal Justice, 6, 43-58.

Filteau, M.R. (2012) Deterring defiance: 'Don't give a poacher a reason to poach'. International Journal of Rural Criminology, 1 , 236-255.

Garicano, L. \& Heaton, P. (2010) Information technology, organization, and productivity in the public sector: evidence from police departments. Journal of Labor Economics, 28, 167-201.

Gore, M.L. (2011) The science of conservation crime. Conservation Biology, 25, 659-661.

HaAs, T.C. \& Ferreira, S.M. (2017) Optimal patrol routes: interdicting and pursuing rhino poachers. Police Practice and Research, http://dx.doi.org/10.1080/15614263.2017.1295243.

Hilborn, R., Arcese, P., Borner, M., Hando, J., Hopcraft, G., Lогвоокі, M. et al. (2006) Effective enforcement in a conservation area. Science, 314, 1266.

JACHMAnN, H. (2008) Monitoring law-enforcement performance in nine protected areas in Ghana. Biological Conservation, 141, 89-99. 
KING, W.R. \& HE, J. (2006) A meta-analysis of the technology acceptance model. Information \& Management, 43, 740-755.

Lapointe, L. \& Rivard, S. (2005) A multilevel model of resistance to information technology implementation. Management Information Systems Quarterly, 29, 461-491.

LemieuX, A.M. (2015). Geotagged photos: a useful tool for criminological research? Crime Science, 4, 3, https://doi.org/10.1186/ S40163-015-0017-6.

Lindsay, R., Jackson, T.W. \& Cooke, L. (2011) Adapted technology acceptance model for mobile policing. Journal of Systems and Information Technology, 13, 389-407.

Manning, P.K. (2008) The Technology of Policing: Crime Mapping, Information Technology, and the Rationality of Crime Control. New York University Press, New York, USA.

Moreto, W.D., Lemieux, A.M. \& Nobles, M.R. (2016) 'It's in my blood now': the satisfaction of rangers working in Queen Elizabeth National Park, Uganda. Oryx, 50, 655-663.

Murray, J.P., Grenyer, R., Wunder, S., Raes, N. \& Jones, J.P.G. (2015) Spatial patterns of carbon, biodiversity, deforestation threat, and REDD+ projects in Indonesia. Conservation Biology, 29, 1434-1445.

Park, N., Serra, E., Snitch, T. \& Subrahmanian, V. S. (2015) APE: a data-driven, behavioral model-based anti-poaching engine. IEEE Transactions on Computational Social Systems, 2, 15-37.

Sintov, N., Kar, D., NGuyen, T., Fang, F., Hoffman, K., Lyet, A. \& TAmbe, M. (2016) From the lab to the classroom and beyond: extending a game-based research platform for teaching AI to diverse audiences. In Proceedings of the 6th Symposium on Educational
Advances in Artificial Intelligence, pp. 4107-4112. Association for the Advancement of Artificial Intelligence Press, Palo Alto, USA.

Tамве, M. (2011) Security and Game Theory: Algorithms, Deployed Systems, Lessons Learned. Cambridge University Press, New York, USA.

Venkatesh, V. \& Bala, H. (2008) Technology acceptance model 3 and a research agenda on interventions. Decision Sciences, 39, 273-315.

Yang, R., Ford, B., Tambe, M. \& Lemieux, A. (2014) Adaptive resource allocation for wildlife protection against illegal poachers. In Proceedings of the 2014 International Conference on AAMAS, pp. 453-46o. International Foundation for Autonomous Agents and Multiagent Systems, Richland, USA.

\section{Biographical sketches}

NicOLE Sintov is an environmental psychologist whose research focuses on developing and evaluating interventions to change behaviour, particularly related to the adoption and use of conservation technologies. Viviane SEYRANIAN is a social/conservation psychologist whose research employs insights from social psychology to design and test communications and educational interventions that seek to promote sustainable lifestyles and increased well-being. ARNAUD LYET is a conservation scientist who focuses on analysis and management of animal populations and is especially interested in the monitoring and conservation of rare, elusive and threatened large mammal species. 